\title{
PENGOLAHAN MOTIF BATIK PERPADUAN UNSUR TRADISI JAWA DAN JEPANG
}

\author{
Morinta Rosandini, M.Ds. ${ }^{1}$ \\ Imam Syafrudien AS, SE ${ }^{2}$ \\ (1) Program Studi Kriya Tekstil dan Mode, \\ Fakultas Industri Kreatif, Universitas Telkom \\ (2) Ilmu Ekonomi Studi Pembangunan \\ Fakultas Ekonomi, Universitas Islam Indonesia
}

\begin{abstract}
PPI Ishikawa as one of the Indonesian student community in Japan invited Batik practitioners to design Batik motif, that not only has elements of traditional culture but also represents the character of that community. The purposes were to rise a pride of that community and to introduce Batik as Indonesian culture to local residents as well. Therefore, to fulfill those purposes, it is needed a research in designing Batik motifs that combine traditional Javanese ornaments as the original character of Batik and Japanese elements as a culture that developed around the community. The purpose of this research was to create ornaments pattern composition applied to Batik technique.

The research method used was by conducting qualitative methods, including a literature study for data collection, an exploratory study of the elements of Javanese and Japanese culture, and an experiment on Batik Tulis technique. The result of this research was Batik cloth sheet with 'Truntum' motif as a character of Javanese Batik, combined with the statute of cherry blossom, pagoda, and heron motifs as a character of Japan.
\end{abstract}

Keywords : motif, pattern, Batik, Java, Japan

\section{PENDAHULUAN}

Batik sebagai wastra warisan Indonesia berkembang dari masa ke masa. Menurut Sunarya (2013) pada perkembanganya di dunia modern saat ini Batik secara makna, prinsip, tujuanm dan pengaruh keragaman budaya Indonesia telah meluas ke berbagai bentuk pemahaman. Pada tahun 2009 setelah UNESCO meresmikan Batik sebagai warisan tak benda dari Indonesia, perkembangan Batik semakin pesat. Hal tersebut ditandai dengan muncul nya Batik modern yang berciri khas lokal dari berbagai wilayah di Indonesiam salah satunya adalah Batik Kota Bekasi, Batik Kota Cimahi, hingga Batik Kab. Bogor. Batik 
modern tersebut muncul sebagai upaya pelestarian budaya dari kearifan lokal daerah (Sunarya : 2013).

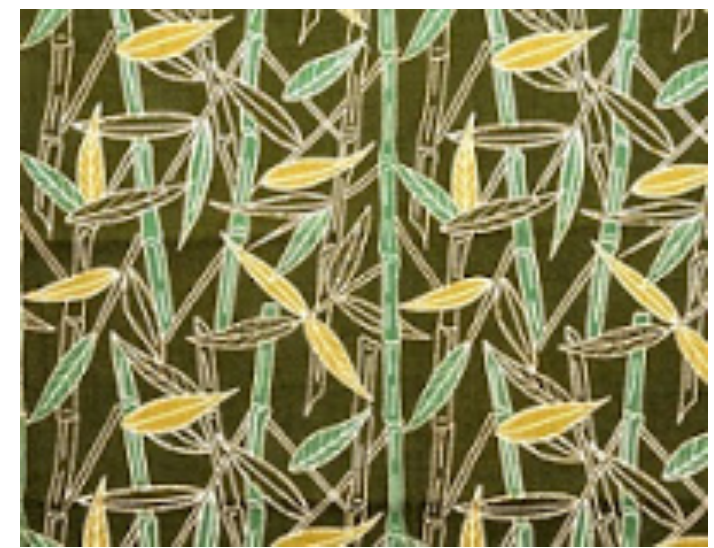

Gambar 1 Batik Ciawi Tali Cimahi. (Sumber : https://infocmh.blogspot.co.id/2013/12/yukmengenal-berbagai-motif-batik-khas.html, diakses pada November 2017)

Perkembangan batik modern tidak hanya terjadi di dalam negeri, berbagai komunitas Indonesia di luar negeri pun melakukan inovasi desain batik modern yang memiliki konten lokal Indonesia. Hal ini dilakukan sebagai upaya menunjukkan ciri khas ke-Indonesian-an serta menciptakan ikon komunitas tersebut.

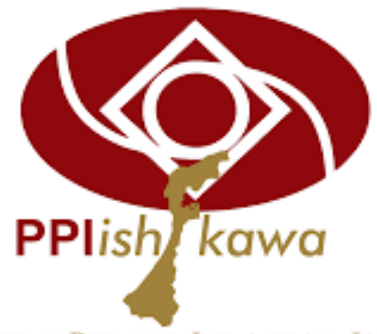

PERSATUAN PELAJAR INDONESIA ISHIKAWA

Gambar 2 Logo PPI Ishikawa Jepang. (Sumber : http://ishikawa.ppijepang.org/, diakses pada Juni 2017)

Salah satu komunitas Indonesia di luar negeri yang melakukan hal tersebut adalah PPI Ishikawa Jepang. Pada tahun 2017 mereka membuka sayembara desain batik khusus untuk desainer motif Indonesia, untuk merancang desain batik yang memiliki perpanduan unsur budaya antara Indonesia dan Jepang. Batik ini kemudian akan dijadikan ikon seragam bagi PPI Ishikawa, Jepang.

Peneliti melihat adanya peluang tersebut untuk dapat mengolah visual motif batik dengan tujuan untuk membuat sebuah inovasi desain batik modern yang berbau lokal dan memiliki perpaduan budaya Indonesia, khususnya Jawa, dan Jepang, yang kemudian diterapkan dengan teknik batik.

Dokumen ini adalah template Jurnal Rupa dalam versi Word (doc). Anda dapat menggunakan template ini dalam menyusun naskah penelitian Jurnal Rupa. Pendahuluan menguraikan latar belakang permasalahan, isu-isu/fenomena yang berkaitan dengan masalah yang diselesaikan, ulasan dari penelitian yang pernah dilakukan sebelumnya oleh peneliti lain yang relevan dengan penelitian yang dilakukan.

\section{METODE PENELITIAN}

Metoda penelitian yang dilakukan dengan menggunakan metoda kualitatif, dengan metoda pengumpulan data sebagai berikut:

1. Studi literatur,

2. Eksperimen

3. Eksplorasi 


\section{HASIL DAN ANALISIS}

\section{Tahapan Review}

\section{Batik dan Karakter Visual pada Batik}

Batik dalam definisi kata berasal dari dua kata yaitu; rambataning dan titiktitik yang berarti kumpulan dari titiktitik atau rangkaian titik-titik (Honggopuro:2002). Berdasarkan Sunarya (2013) batik adalah cara penerapan corak di atas kain melalui proses celup rintang warna dengan malam sebagai medium perintangnya.

Karakter batik tradisional Indonesia terlihat pada motif dan warna nya. Menurut Kusrianto (2013) budaya Jawa banyak menggunakan simbol atau lambang, sama hal nya pada batik. Selain memiliki keindahan estetika, motif batik klasik banyak mengandung arti bagi orang Jawa. Masih menurut Kusrianto (2013) bahwa struktur dasar pola batik terdiri dari 3 komponen penyusun; (1) Komponen Utama, unsur pokok dari motif batik, (2) Komponen Pengisi, motif yang dibuat untuk mengisi bidang diantara motif utama, (3) Isen-isen, memiliki fungsi untuk memperindah pola batik, biasanya berbentuk titik, garis atau lingkaran yang disusun berulang.

Salah satu batik klasik Jawa yang banyak dikenal adalah Batik Truntum. Truntum adalah motif batik dengan latar belakang berwarna gelap antara warna cokelat soga hingga warna biru kehitaman. Makna dalam pada batik truntum adalah cinta dan kasih sayang (Kusrianto : 2013).

\section{Karakter Motif Jepang}

Hampir serupa dengan kepercayaan pada budaya Jawa, simbol dan lambing atau motif sudah menjadi bagian yang menyatu dalam estetika budaya Jepang, baik dalam unsur desain pada tradisi maupun moden (Aung:2015).

Terdapat beberapa simbol alam yang dipercaya memiliki makna dan tertuang pada motif, salah satunya antara lain, bunga Sakura dan burung Bangau.

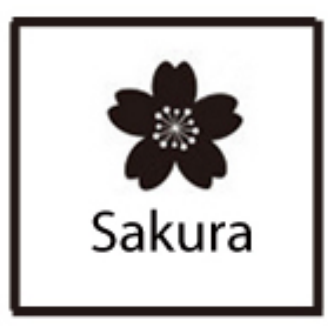

Gambar 3 Bunga Sakura (Sumber : https://nalatanalata.com/journal/motifs-injapanese-design/, diakses pada Juni 2017)

Menurut Aung (2015) pada jurnal nya dijelaskan bahwa sejak Periode Heian, bunga sakura telah dipercaya oleh Jepang dan berkaitan erat dengan kefanaan hidup dan apresiasi untuk keindahan yang singkat. 


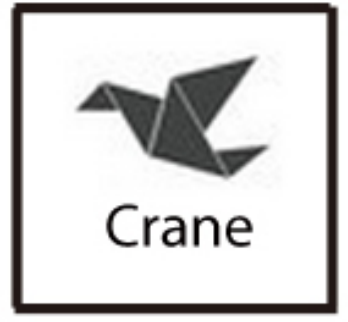

Gambar 4 Burung Bangau (Sumber : https://nalatanalata.com/journal/motifs-injapanese-design/, diakses pada Juni 2017)

Crane atau burung bangau, merupakan simbol umum yang dipakai oleh orang Jepang sebagai simbol umur panjang dan keberuntungan. Jepang juga memiliki budaya kepercayaan untuk melipat seribu origami burung bangau untuk mewujudkan impian jadi nyata.

\section{Perpaduan unsur budaya Indonesia dan Jepang - Batik Jawa Hokokai}

Pada perkembangan nya Batik mendapatkan beberapa pengaruh dari budaya asing yang masuk ke Indonesia pada zaman sebelum merdeka. Salah satunya adalah pengaruh budaya Jepang, hal ini dapat terlihat pada Batik Jawa Hokokai. Menurut Kusrianto (2013:275-277) Batik Jawa Hokokai adalah Batik yang muncul pada periode penjajahan Jepang (19421945) sebagai tanda "penyesuaian" kepada penguasa baru agar para pembatik mendapatkan tempat pada masa tersebut. Batik ini pada awalnya dipesan oleh lembaga Jawa Hokokai (organisasi yang dibentuk oleh Jepang di Indonesia) untuk orang-orang Indonesia yang telah berjasa dalam propaganda Jepang.
Masih menurut Kusrianto (2013) ciri khas dari Batik Jawa Hokokai telihat dari dominasi motifnya yang paling sering muncul adalah bunga sakura.

Berdasarkan pemahaman mengenai batik dan perpadua budaya yang sudah ada, maka sangat dimungkinkan adanya perpaduan dua unsur budaya visual Jawa dan Jepang, hal tersebut pula yang menjadi dasar pada perancangan batik untuk keperluan PPI Ishikawa.

\section{Proses Pengolahan unsur Visual Budaya}

Proses pengolahan unsur visual motif batik dilakukan dengan proses studi literasi dan observasi motif batik dan simbol motif pada budaya Jepang.

Dalam upaya mewujudkan rancangan desain motif batik Indonesia dan Jepang untuk desain motif Batik PPI Ishikawa, Jepang dilakukan dengan beberapa tahapan yang, antara lain :

1. Melakukan studi literatur berkaitan dengan pemahaman Batik, unsur budaya Jawa dan unsur budaya Jepang,

2. Mengolah image board sebagai landasan inspirasi dalam merancang komposisi motif batik,

3. Melakukan stilasi bentuk dari visual image board hingga menghasilkan modul motif,

4. Eksperimen komposisi pola motif dari bentuk modul stilasi motif, 
5. Prose tracing digital dan penerapan warna menggunakan teknik digital,

6. Proses Membatik.

\section{Image board, inspirasi karya}

\section{Kanaka Batik \\ I mage Board}

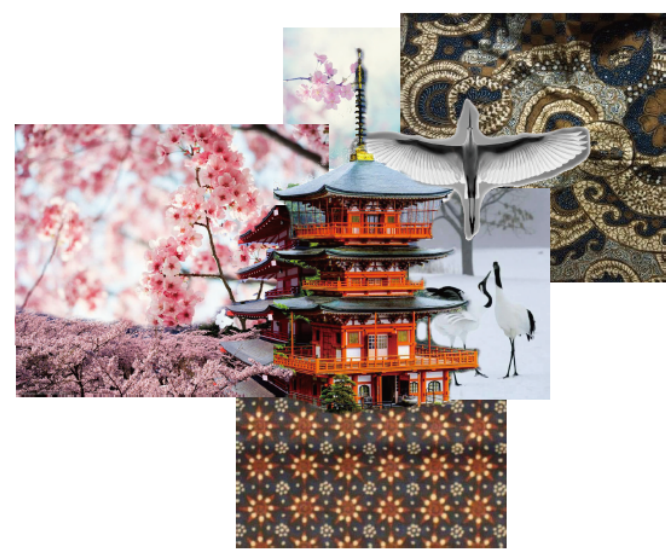

Gambar 5 Image Board Batik Kanaka

Sumber : Dokumentasi Pribadi (2017)

Pada perancangan ini tema yang diangkat adalah Kanaka. Dengan mengusung konsep sebagai berikut :

KANAKA dalam bahasa Sansekerta berarti emas, sesuatu yang sangat berharga. Kanaka Batik hadir dalam perpaduan konsep budaya Jepang dan Indonesia, karena budaya adalah produk cipta karsa yag berharga. Unsur budaya dan alam Jepang menjadi salah satu fokus utama dalam desain Kanaka Batik; Arsitektural Kumano Nachi Taisha, Burung

Bangao sebagai lambang good fortune dan Bunga Sakura sebagai makna mono no aware. Ketiga unsur tersebut dipadukan dalam sebuah komposisi yang menajamkan karakter Jepang, sedangkan unsur bentuk Batik Truntum menjadi unsur penguat budaya Jawa. Batik truntum memiliki makna cinta dan kasih sayang yang mendalam, begitu juga dengan Kanaka Batik yang menjadi harapan bagi siapapun yang memakainya menjadi simbol kebaikan, rasa peduli, dan sejauh apapun melangkah rasa cinta terhadap tanah air tetap tertanam dalam hati sanubari. Warna sogan (coklat tua kehitaman) menjadi ciri khas Batik Kanaka yang juga merupakan ciri khas batik Jawa Klasik. Warna coklat keemasan menguatkan makna Kanaka dalam batik ini.

\section{Proses Stilasi Manual dan Eksperimen Komposisi}

Proses selanjutnya adalah menerapkan mengaplikasikan konsep desain tersebut pada modul motif. Stilasi bentuk pada image board menjadi langkah pertama. Berikut merupakan tahapan proses stilasi manual hingga eksperimen komposisi. 


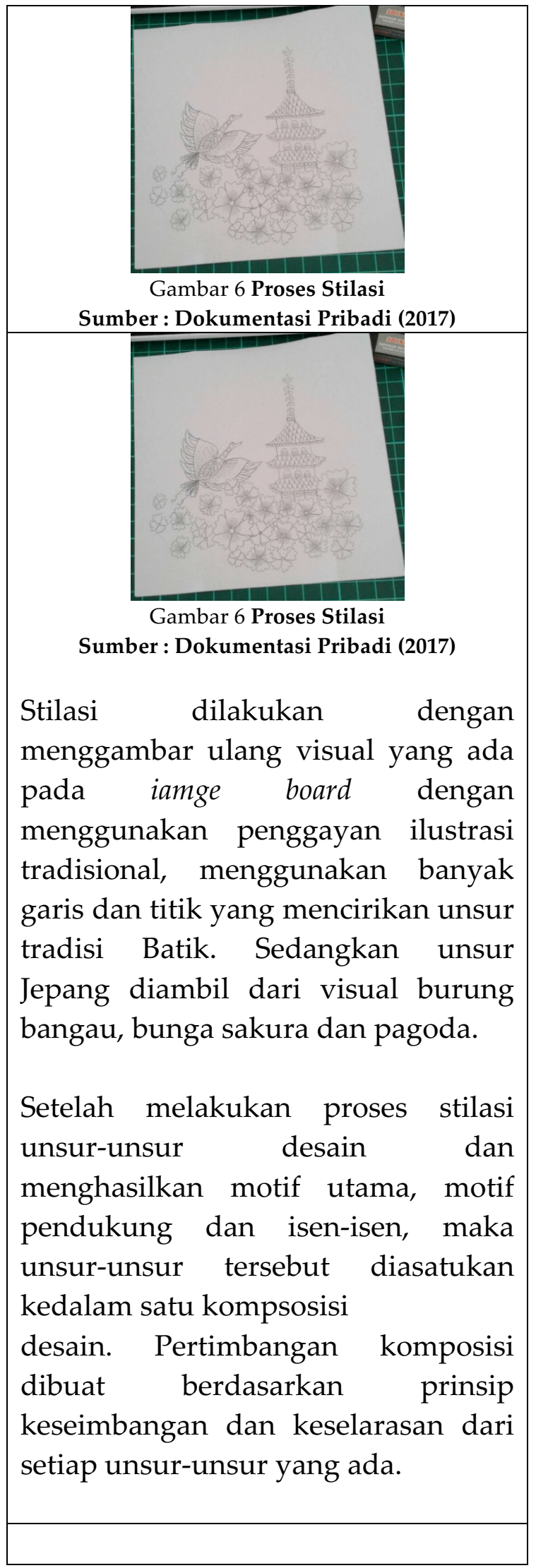

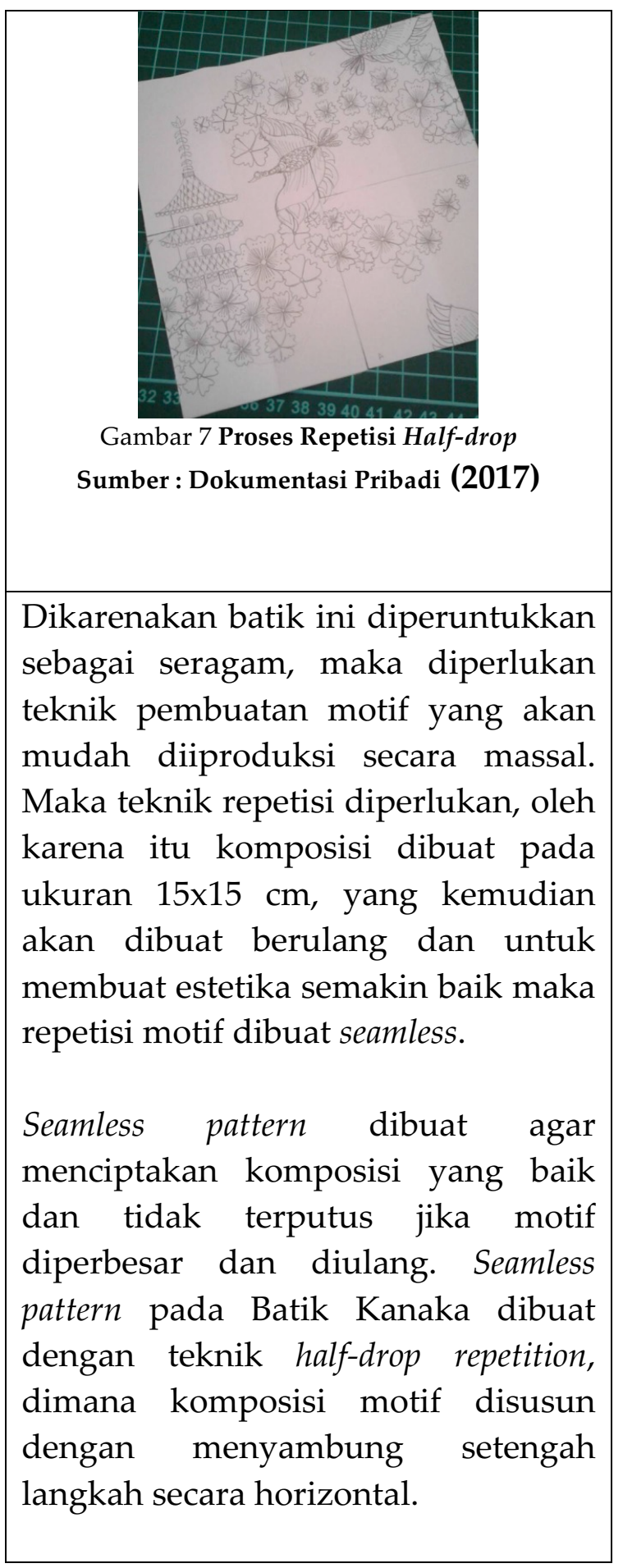




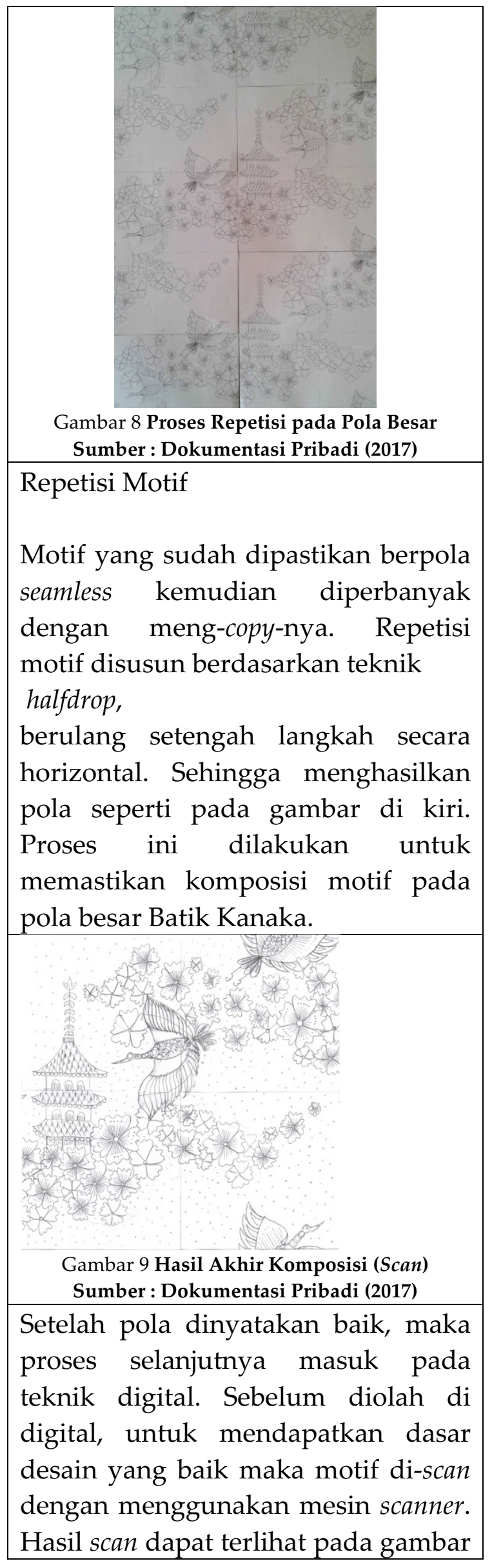

di samping.

\section{Proses Pengolahan Visual pada Digital}

\begin{tabular}{|l|l|}
\hline Inspirasi & $\begin{array}{l}\text { Proses } \\
\text { Pengolahan } \\
\text { Stilasi Digital }\end{array}$ \\
\hline & \\
\hline
\end{tabular}

Proses stilasi digital dilakukan dengan mengikuti desain motif hasil scan pada pengolahan stilasi manual. Sehingga dihasilkan motif pada gambar di atas. Tiga motif utama ditracing dengan menggunakan software design, dilakukan dengan menorehkan garis-garis sehingga membentuk bentuk yang utuh.

\section{Proses Komposisi Warna}

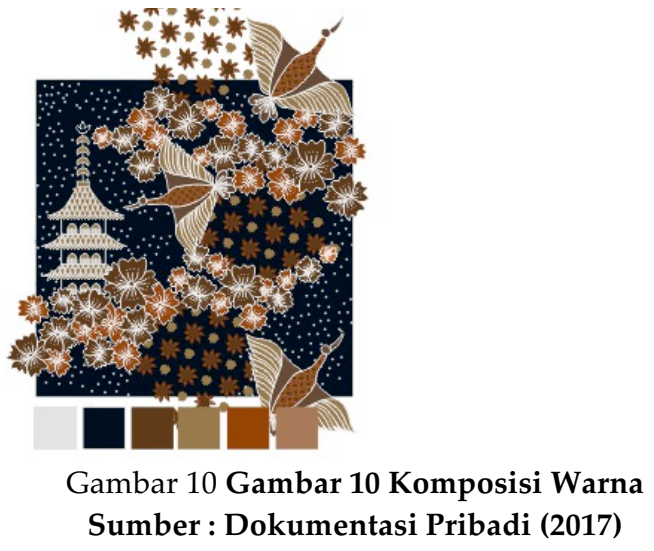

Hasil tracing dari unsur-unsur motif kemudian dikomposisikan sesuai dengan sketsa awal. Pewarnaan 
Digital disesuaikan dengan warna pada Image Board.

\section{Proses Repetisi Digital}

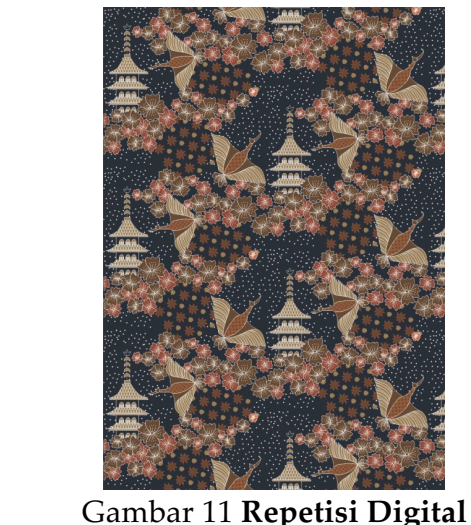

Sumber : Dokumentasi Pribadi (2017)

Proses repetisi digital dilakukan setelah proses pewarnaan selesai dengan tetap memastikan pola seamless pattern. Motif Batik Kanaka direpetisi

pada ukuran A4. Dengan selesai nya proses repetisi pada digital maka Batik Kanaka siap memasuki proses Batik.

\section{Proses Batik}

Proses pengerjaan Batik Kanaka bekerjasama dengan pengrajin di Pekalongan. Proses ini dilakukan dengan berkolaborasi dengan Imang Jasmine Batik yang memiliki kemampuan batik yang mumpuni dan karakter batik yang kuat. Teknik dilakukan dengan dua kali babaran (proses canting-celup-lorod) membuat batik memiliki teknik yang advanced dengan tujuan menonjolkan beberapa point-of-interest dari motif batik yang sudah ada.

Berikut merupakan tahapan proses membatik Batik Kanaka :

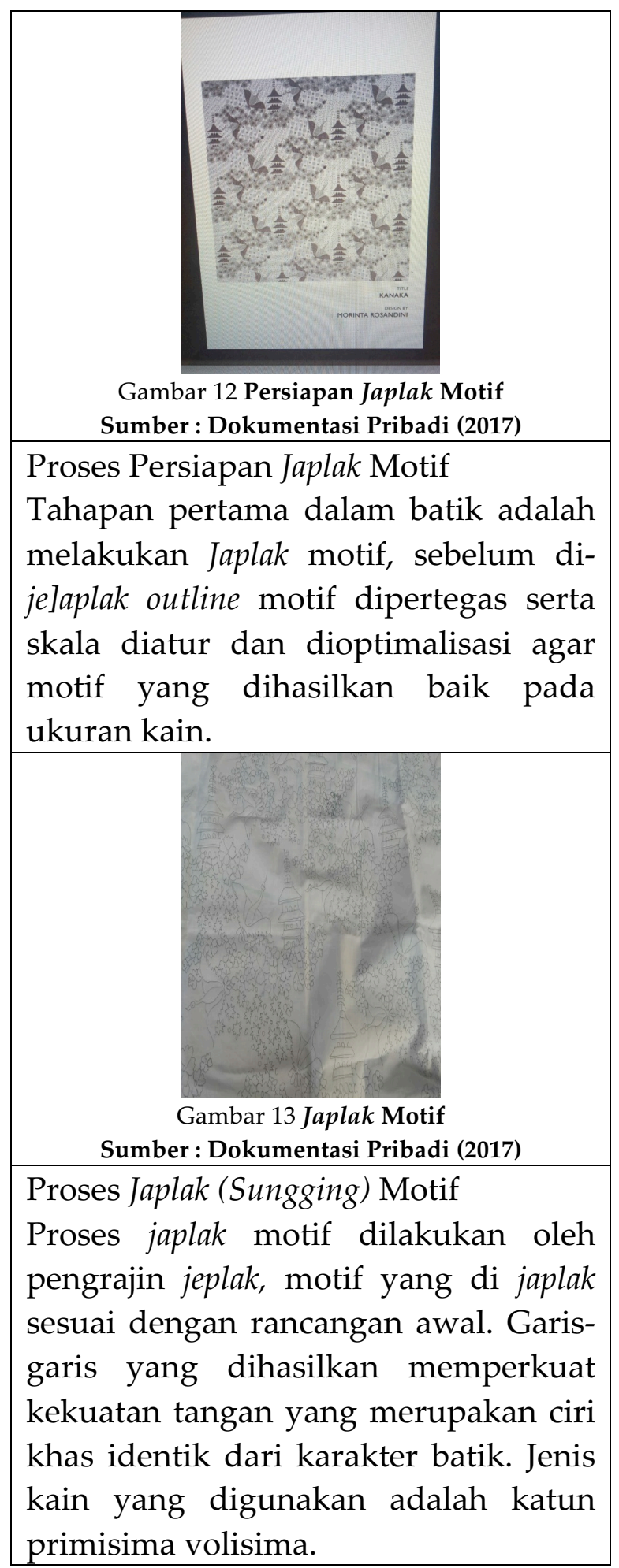




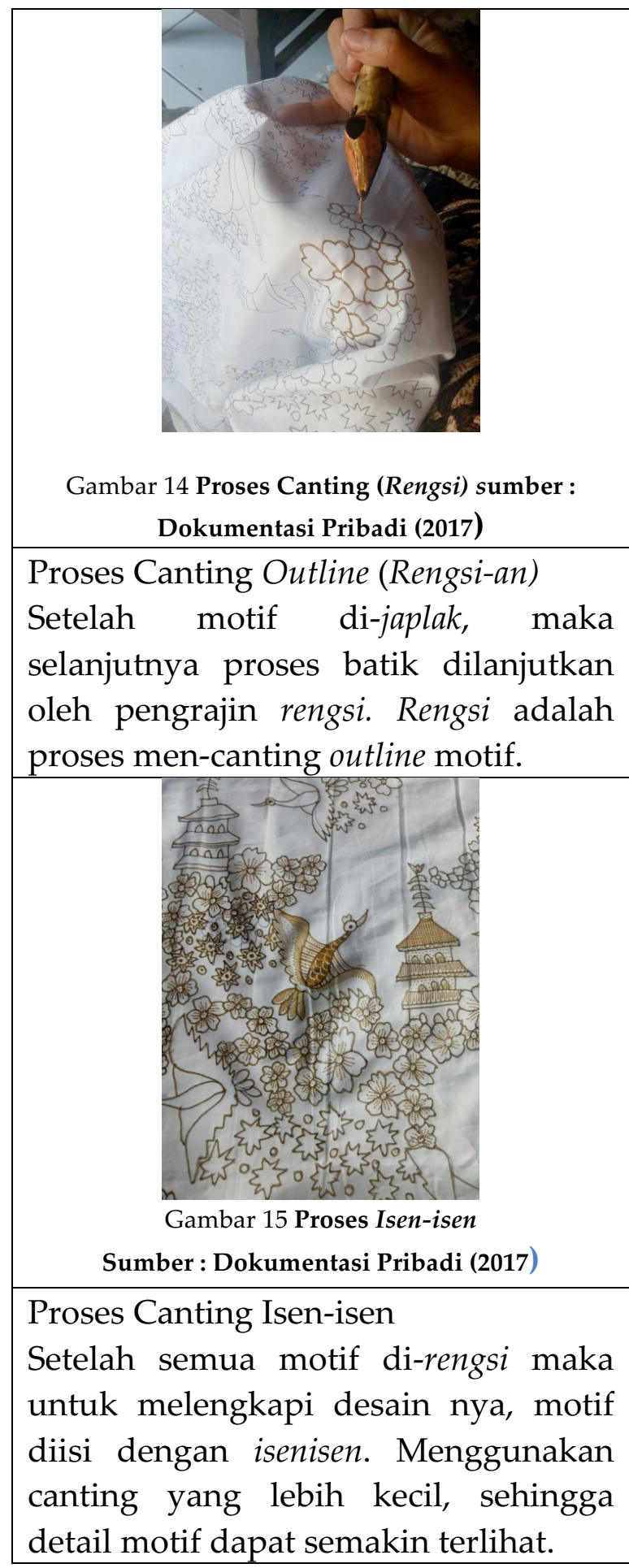

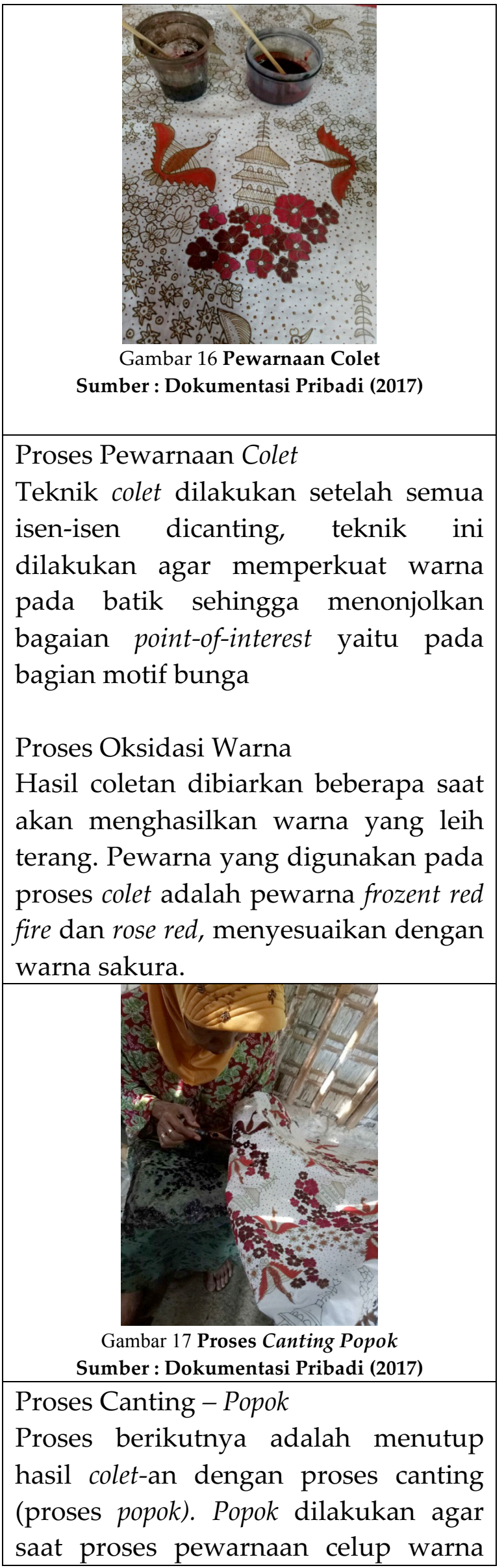




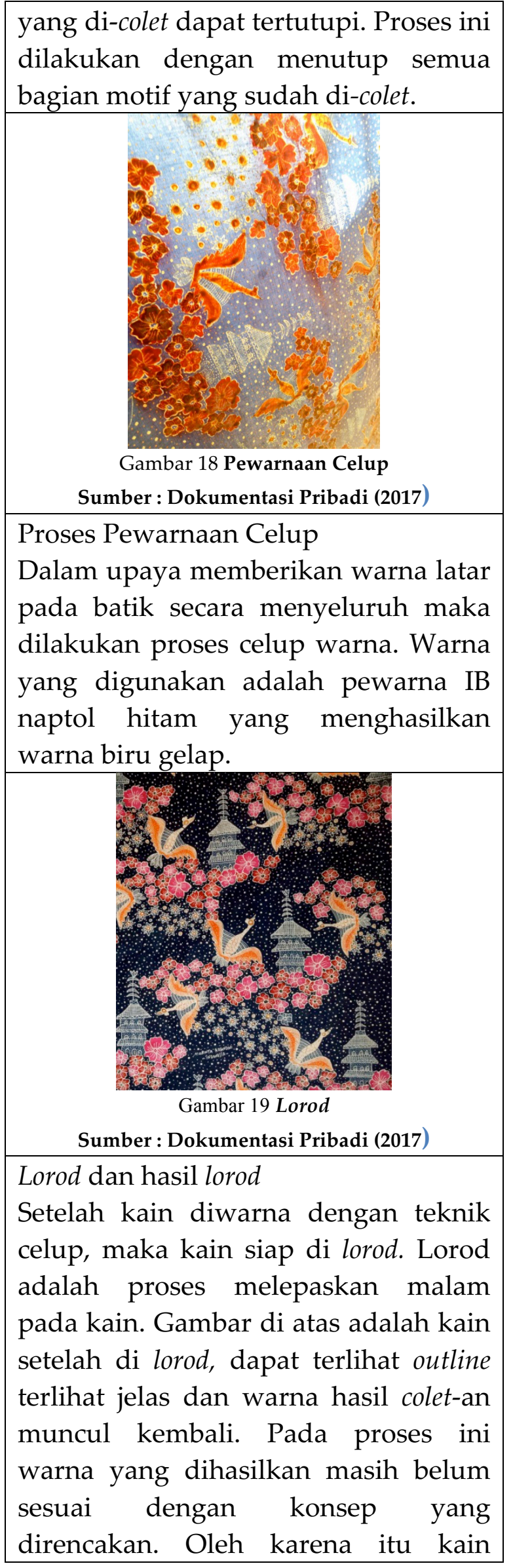

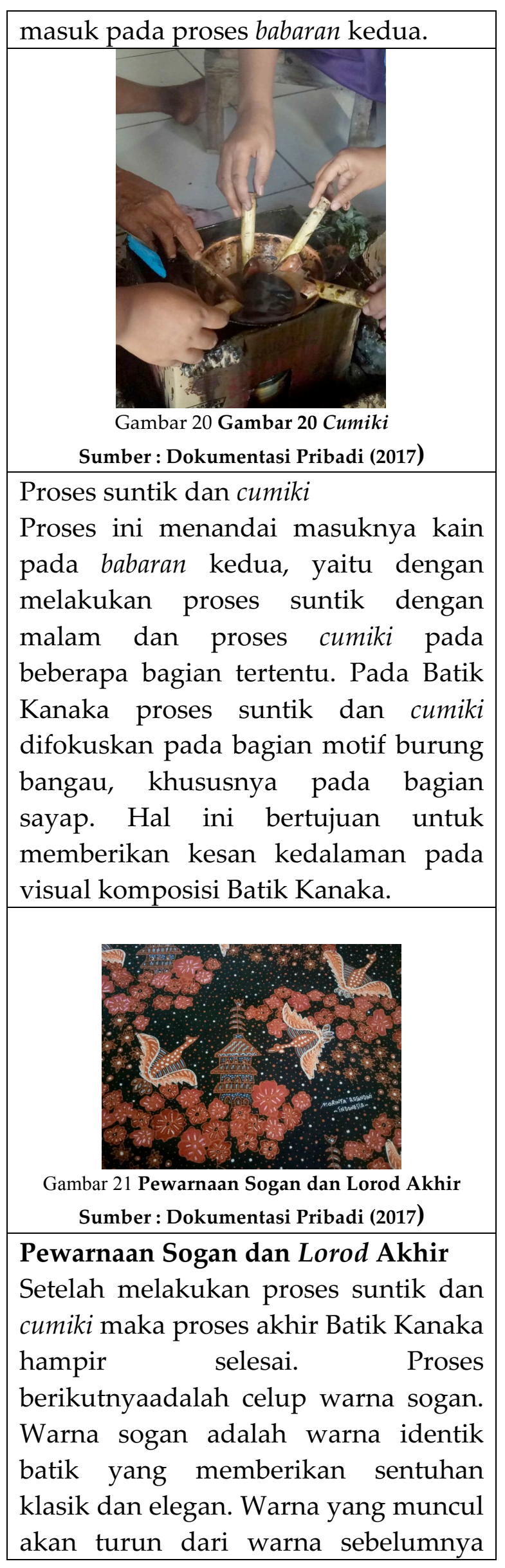


dikarenakan adanya percampuran warna awal dengan warna sogan. Setelah proses pewarnaan sogan selesai, maka proses selanjutnya adalah lorod, untuk menghilangkan malam dari proses suntik sebelumnya. Setelah di lorod maka kain yang dihasilkan adalah seperti pada gambar di atas. Warna akhir yang dihasilkan sedikit berbeda dengan konsep awal, dikarenakan pertimbangan estetika pada saat proses pembatikan. Namun dengan perbedaan warna ini tidak merubah konsep awal dari Batik Kanaka. Warna coklat sogan memberikan makna berharga seperti emas (kanaka).

\section{Hasil}

Hasil dari penelitian ini berupa lembaran kain Batik dengan motif batik perpaduan motif truntum sebagai ciri khas batik Jawa dan stilasi bunga sakura, pagoda serta burung bangau yang merupakan ciri khas Jepang, yang diberi tajuk Batik Kananka.

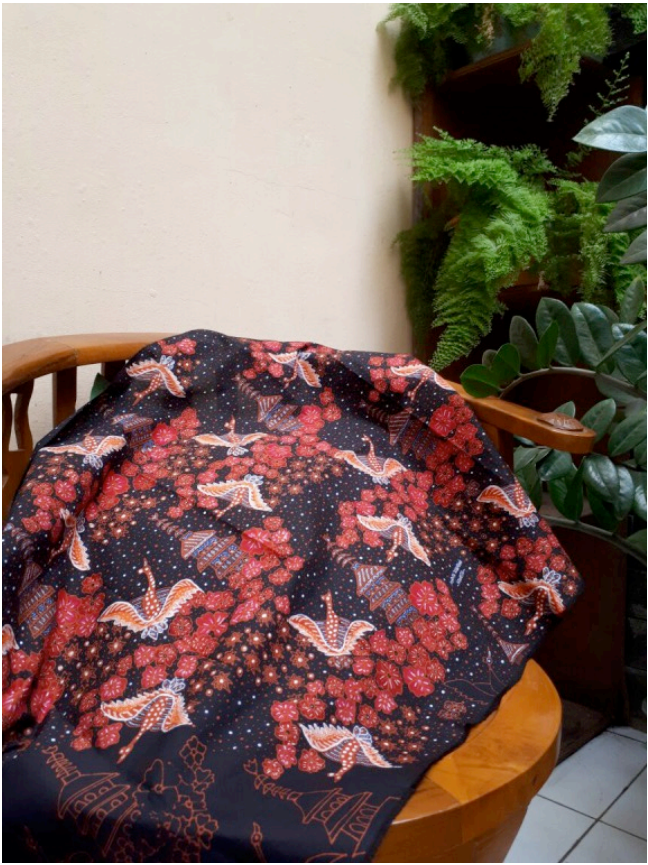

Gambar 22 Gambar 22 Hasil Akhir Batik Kanaka Sumber : Dokumentasi Pribadi (2017)

\section{SIMPULAN}

Budaya Batik berkembang pesat, dari tradisi hingga modern saat ini hal tersebut terlihat dari perkembangan bentuk visual motif yang ada pada batik. Kebutuhan akan identitas yang dicirikan dengan menggunakan batik meluas hingga luar negeri. Salah satunya adalah upaya PPI Ishikawa dalam melestarikan batik dengan mengadakan sayembara. Dengan menciptakan Batik Kanaka yang diikut sertakan pada sayembara tersebut membutikan bahwa budaya batik dapat berdaptasi dengan berbagai budaya tanpa menghilangkan ciri khas tradisi Jawa dan Indonesia. Batik Kanaka menjadi salah satu contoh batik modern yang memiliki ciri khas Jepang dengan mempertahankan karakter Batik yang berasal dari Jawa, Indonesia.

\section{REFERENSI}


Aung, Stevenson. 2015. Motifs in Japanese Design. https://nalatanalata.com/jou rnal/motifs-in-japanesedesign/ diakses pada Juni 2017.

Honggopuro, KRT.DR.(HC)

Kalinggo. 2002. Bathik

Sebagai Bisana dalam

Tatanan dan Tuntunan.

Surakarta : Yayasan Peduli

Keraton Surakarta

Hadiningrat.

Kusrianto, Adi. 2013. Batik, filosofi, motif dan kegunaan. Yogyakarta : Penerbit Andi.

Sunarya, Yanyan. 2013. Batik dalam Konteks Desain dan Kreatifitas Kini. https://www.researchgate. net/publication/305881821 Batik_dalam_Konteks_Des ain_dan_Kreatifitas_Kini diakses pada Juni 2017. 